\title{
Advanced Modeling Techniques for Architectural Design Education
}

\author{
Arne Riekstins, University of Monterrey
}

\begin{abstract}
This article discusses the usage of advanced modeling techniques in architectural design education from the viewpoint of CAD/CAM paradigm that is setting new standards for the teaching and the industry. Parametricism is one of the main driving forces in architecture that exercises complexity possible only through 3D modeling tools and using generative algorithms. Most of the design skills are being learned by applying the obtained knowledge in academic design projects and their supplementary classes.
\end{abstract}

Keywords - Architectural design education, CAD/CAM paradigm, form finding, generative design, rapid prototyping.

\section{INTRODUCTION}

The communication of an architectural design project by default is the selling point of any idea when it is being presented to the clients. Usage of advanced modeling techniques and rapid prototyping models can facilitate the process of architectural idea presentation significantly, because these technologies allow understanding features that are very hard to present in 2D drawings or photorealistic renderings. The tools for representing the ideas are becoming more sophisticated and interactive, following the current trend of architectural design that is constantly surprising with ever more complex and advanced formal grammars. Universities teaching architectural design around the world are updating their curriculums by including new subjects that are reinforcing the technological advances in the field. The design industry is all the time borrowing new technology from other fields of engineering. It is a very challenging task to be updated in academia, as it involves a comprehensive approach to cover all aspects of the design and its representation - as well as the supporting theoretic background, teaching of the latest modeling tools, self-criticism and artistic freedom for decision making, original creativity in form finding, and the skills to program and operate many types of contemporary digital fabrication machinery. This article explores the ways to implement the latest know-how into the architectural design education through innovative experience carried out in University of Monterrey, Mexico.

\section{CAD/CAM Paradigm Shift}

CAD/CAM paradigm has set new standards in the field of teaching architectural design, as the contemporary practice has raised the demands for standard skillset expected from future architects once they graduate and enter the design offices. Digital systems that allow designing directly for manufacturing has returned the production and responsibility for giving engineering solutions back to architects. And parametricism in contemporary academic environment is one of the main driving forces of architecture that exercises the exploration of complexity, possible only through $3 \mathrm{D}$ modeling tools. Therefore the usage of advanced technology in representing complex ideas becomes a standard procedure. Architects are no more obliged to make detailed drawings that in hands of construction workers are being materialized by their level of understanding or their creative interpretations while solving certain details with real building materials. The paper as the media for communication is becoming almost obsolete and the only way of ensuring high precision quality of the work is to have a full control of the design in all of its phases. That involves many new scenarios for cooperation with structural engineers, parametric programmers, CAD technicians and persons supervising the construction work [5]. One part of the work is a shared digital file management and clearly defined roles of responsibility of each participating member. Some progressive Building Information Management (BIM) systems like CATIA or Frank Gehry Digital Systems can maintain the full range of CAD/CAM applications and also provide the tool palettes with parametrically associative systems for the state of the art design.

\section{Advanced Modeling Methodology and Form Finding}

In year 1996, the Media Laboratory of the Massachusetts Institute of Technology (MIT) established The Aesthetics and Computation Group as an experimental research studio for integrating the technology into the design and soon received numerous notable awards by their graduates [1]. As soon as academic experimentation with lots of freedom was applied to the designs by the use of advanced CAD modeling, the projects gained added value in both technical complexity and artistic value. The innovation occurs by doing new research that has not been documented before. Therefore the availability to analyze the built examples of digitally derived parametrical architectural projects gives more interest for students in architectural design to explore the complexity of form and function. Usually it involves also developing the concepts for structural engineering, or in other words - understanding constructability.

Judging by the latest trends, the development of digital design did not end with using simple parametric modeling; it has taken a step ahead by using generative algorithms. Several software packages offer graphical algorithm editors (e.g. Coffee, Grasshopper), which are directly linked to 3D modeling tools and allow interactive parametric modeling [2]. The simplicity of Grasshopper lies within its direct link to one of the most widely used 3D modeling software Rhinoceros, that controls it with a significant range of tools for mathematical, geometrical and generative operations, as well as statements of conditionals, ad- 
vanced functions and trigonometry. Also the learning curve for its usage is relatively quick as it does not demand skills of coding or programming of pure scripts - all of its elements are organized in an easy to understand visual programming language (VPL) format. In a conceptual parametric design, it is the parameters of a particular design that are declared, not its shape [2, 11]. That allows designers to assign parametric values to geometrical objects that can have different spatial arrangement configurations, thus facilitating the process for form finding. Currently there are dozens of powerful additional plugins available for Grasshopper to facilitate certain specific and repetitive design tasks, individual developers design them and very often these plugins are available in an open source format.

Traditional modes of form creation have given significant weight to quantitative, cognitive and perceptual aspects of the architectural form. Throughout the history of architecture, this idea sustained logocentric modes of operation and theories, which in turn promoted the image-based approaches to form, such as typology and shape grammar. Starting from the late 1960's, the introduction of computers to architectural design ushered in the possibility of using computers to generate architectural form using quantitative data [3]. First documented digital architecture pioneers to explore new forms were John Frazer (1995), Greg Lynn (1999), Branko Kolarevic (2005), Michael Hensel (2006) and Mutsuro Sasaki (2007).

The next crucial element in the teaching process lies in the model making that ensures the communication of a proposal from its early sketch stage to the final detailing of a project. Students who are skilled in 3D modeling will have more capacity to elaborate the complex ideas, whereas students without these skills will need more time and sometimes might end up with more basic project versions just because that is within their modeling abilities. Finally, all of the abovementioned has to be mastered in given time constraints for successfully complying with the expected advance reviews and deliverable amount of final project design materials.

In a very classic architectural education model the students are provided with a set of study courses that support the design productivity starting from freehand sketching to learning CAD design software. Most of the design skills are being learned by applying the obtained knowledge in academic design projects and by taking supplementary classes of any kind where there is a need to strengthen one's knowledge. There have been made comparisons of the design productivity while designing in analog versus digital media and apparently there are differences that have been observed in the workflow patterns, especially in the way how a designer is handling previous and current design decisions [4]. Usually there accumulates an amount of unusable objects that is considered dirt and it may leave indecisive designers in a decision redundancy loop because of having an attachment to the remains of older version of work. Therefore it is very important that students are given project assignments that involve subsequent changes and exploration in the usage of formal languages that originate more from non-standard geometries, as the academic studies is the best moment to experiment very much, mainly with- out worrying about strict budget, regulations and client ambitions, to name a few typical limiting problems that are being faced by many architectural practices. That becomes a prerequisite for using more 3D modeling software like Rhinoceros, Autodesk 3DS Max or Maya etc., because standard architectural libraries that can be found, for example, in Autodesk Revit or Graphisoft ArchiCad, become very restricting in expressing intricate ideas. The following chapter will discuss the academic application of the concepts described above.

\section{Academic Experience and Application}

The University of Monterrey in Mexico adapted new academic study plan in year 2015 that included several consequent theoretically advanced subjects - Morphology and Generative Geometries that are being taught starting from the second semester of the first study year. Both of them are sequels to descriptive geometry and are oriented towards advanced theories and teaching alternative form finding methods, as well as generative and parametric design. All of the design studios are getting direct benefit of the knowledge achieved in these classes, and the student works show an always increasing link of the matter and understanding the vast potential that it is bringing to their designs.

In the class of Generative Geometries students learn to program and analyze several rule-based systems, like Cellular Automata by Steven Wolfram, Game of Life by John Conway, Fractals by Benoit Mandelbrot and L-Systems by Aristid Lindenmayer. All these systems have in common a set of simple rules that simulate complex morphologies that in classical mathematics are considered to be uncontrollable or amorphous, and all of the resulting patterns are usually two-dimensional expressions that depending of the rules may be very repetitive or present complete randomness. That gives us ability to observe a complexity that has generated specific formal characteristics by the way these systems are written by using primitive symbols and the rules that formally specify their distribution in space.

After getting acquainted by these systems that are programmed and documented by renowned mathematicians and exercised for several decades, students of Generative Geometries class were given all of the freedom to come up with their own systems of formal languages that were based on internal spatial relations or parameters of few points, lines, curves, circles or any other basic two-dimensional geometries to generate incremental variations and observe the possible usage for architectural form finding. The internal relations were documented and limited with a set of rules that allow certain variation within designed parameter ranges and in the limits of preset basic boundaries (Fig. 1), using only a combination with as few chosen geometries as possible. In this step authors were looking for secondary connections of the construction points like intersecting of geometries and gradually turning the original layer invisible that was involved to control the primary system of constructed elementary geometries.

From many explored possible spatial arrangements students picked a few potential results that can be viewed as their new archetypal formal language 'letters' as geometries to proliferate 

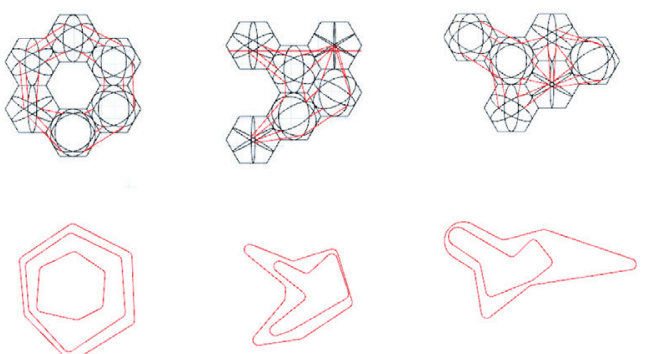
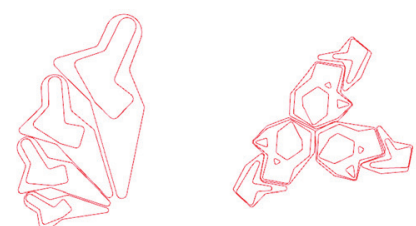

LLLL

EPEPEP
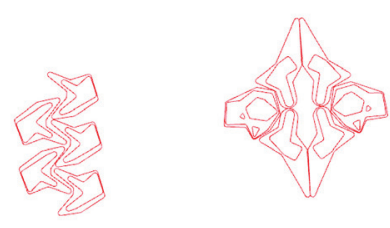

\section{EEEEE}

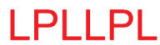

Fig. 1. Simple geometric system in various early stages revealing variations of three ellipses within 6-9 hexagons (above) and the resulting filleted polylines that interconnect the neighbouring ellipse crossing points with original hexagon layer turned invisible (below). The polyline geometries may be considered as first 'letters' [Figure: A. Rodríguez Ramírez].
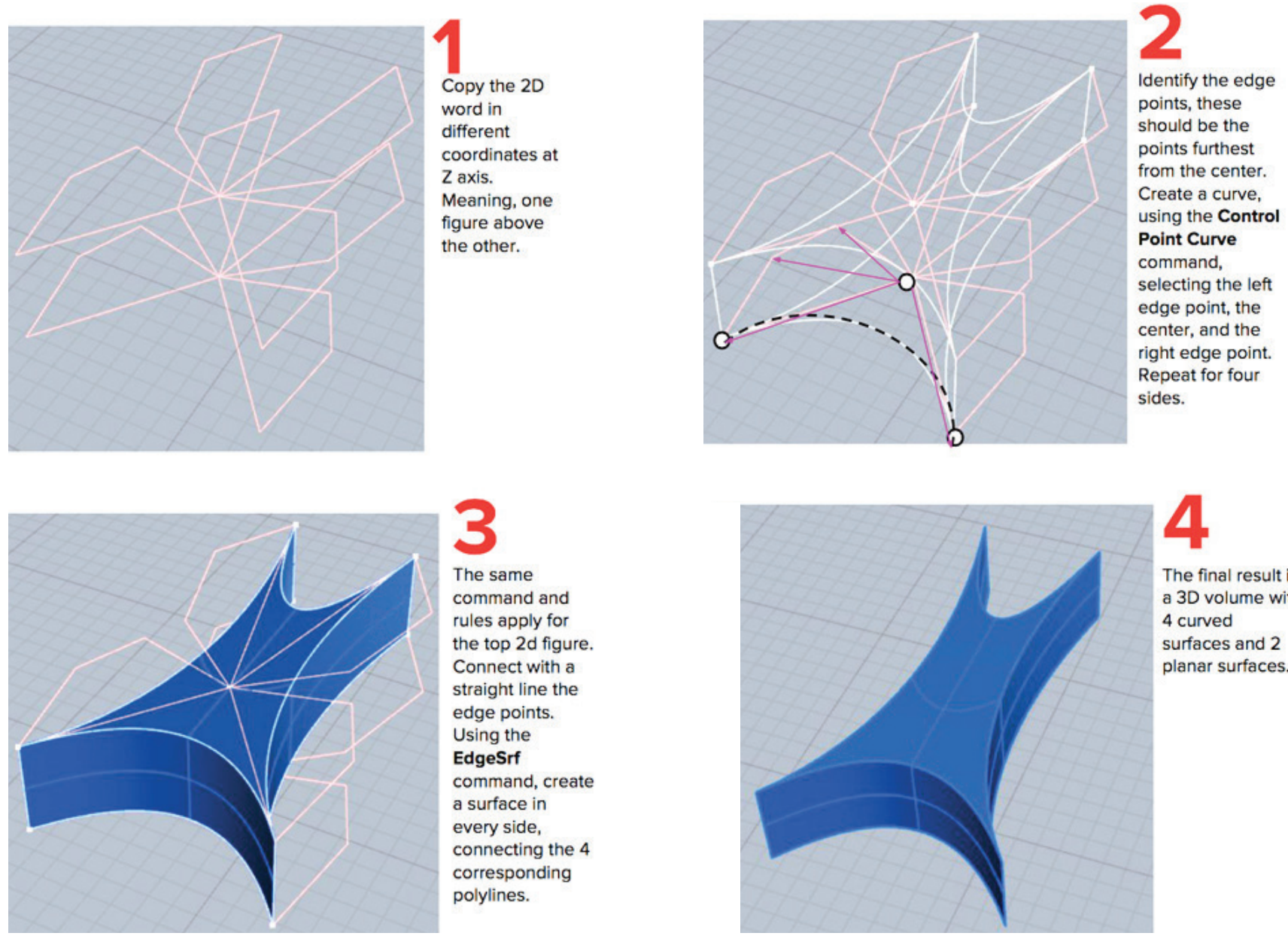

Fig. 2. Exploration of possible arrangements of simple geometric systems into compositional word formations [Figure: A. Rodríguez Ramírez].

the other.
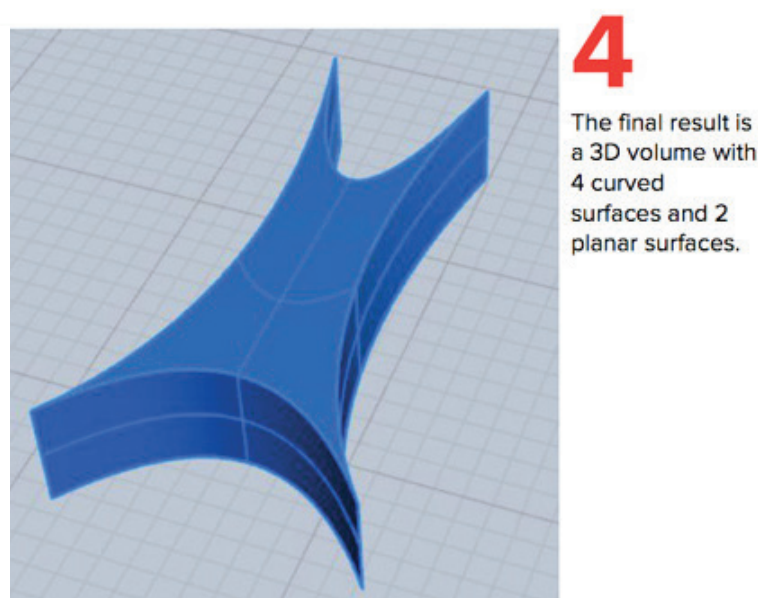

Fig. 3. Materialization in 3D. An example of creating a three-dimensional volumetric figure using two 'simple words' and a four-step rule [Figure: S. Medina].

further formations of the given 'letters' into 'simple words' or small compositions made out of 3-6 'letters' (Fig. 2). Every student explored at least 20 different ways of rearranging the recently generated formal language 'letters' in many small systems to find how they can be regrouped to fit together in a geometric logic, and cataloguing the configurations to find potentially strongest novel and original formations to work with in upcoming next steps. The possible rearrangements to the 'letters' could be the usage of mirror command, moving them in 2D space and finding out which edges can connect, therefore rotating and scaling them to adjust the dimensional differences of the shapes to match into a distinct compositional setting.

The final and last step was constructing and cataloging of 50 volumetric $3 \mathrm{D}$ objects that were materialized using previous 'simple words' proliferations as the templates. As there is no currently documented theory of how this step should be done, individual 

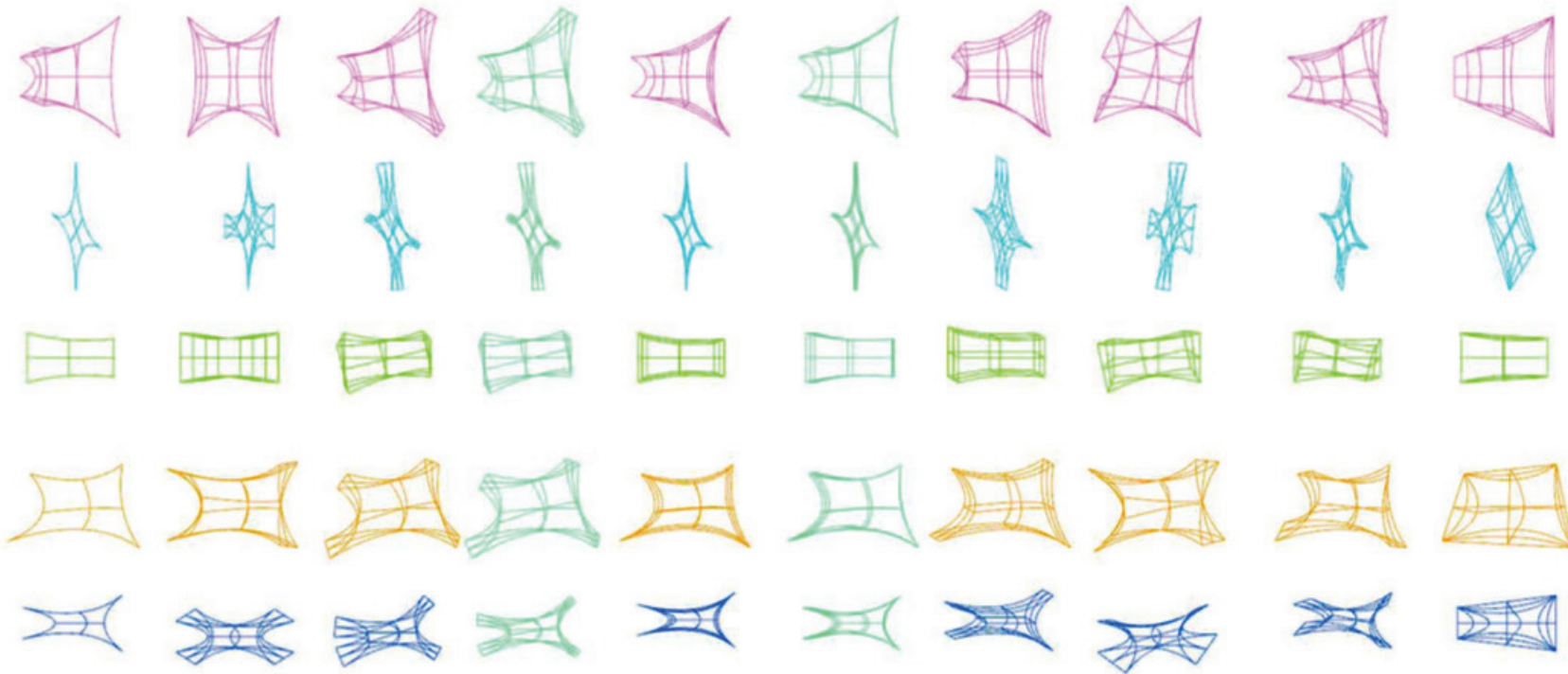

Fig. 4. A catalogue of 50 variations of 5 base volumes materialized in 3D [Figure: S. Medina].

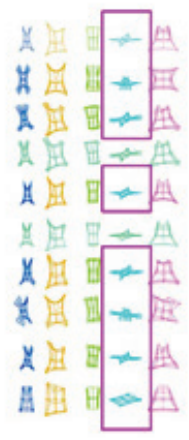

\section{The fourth level} consist of the variations and base figures from letter $E$.
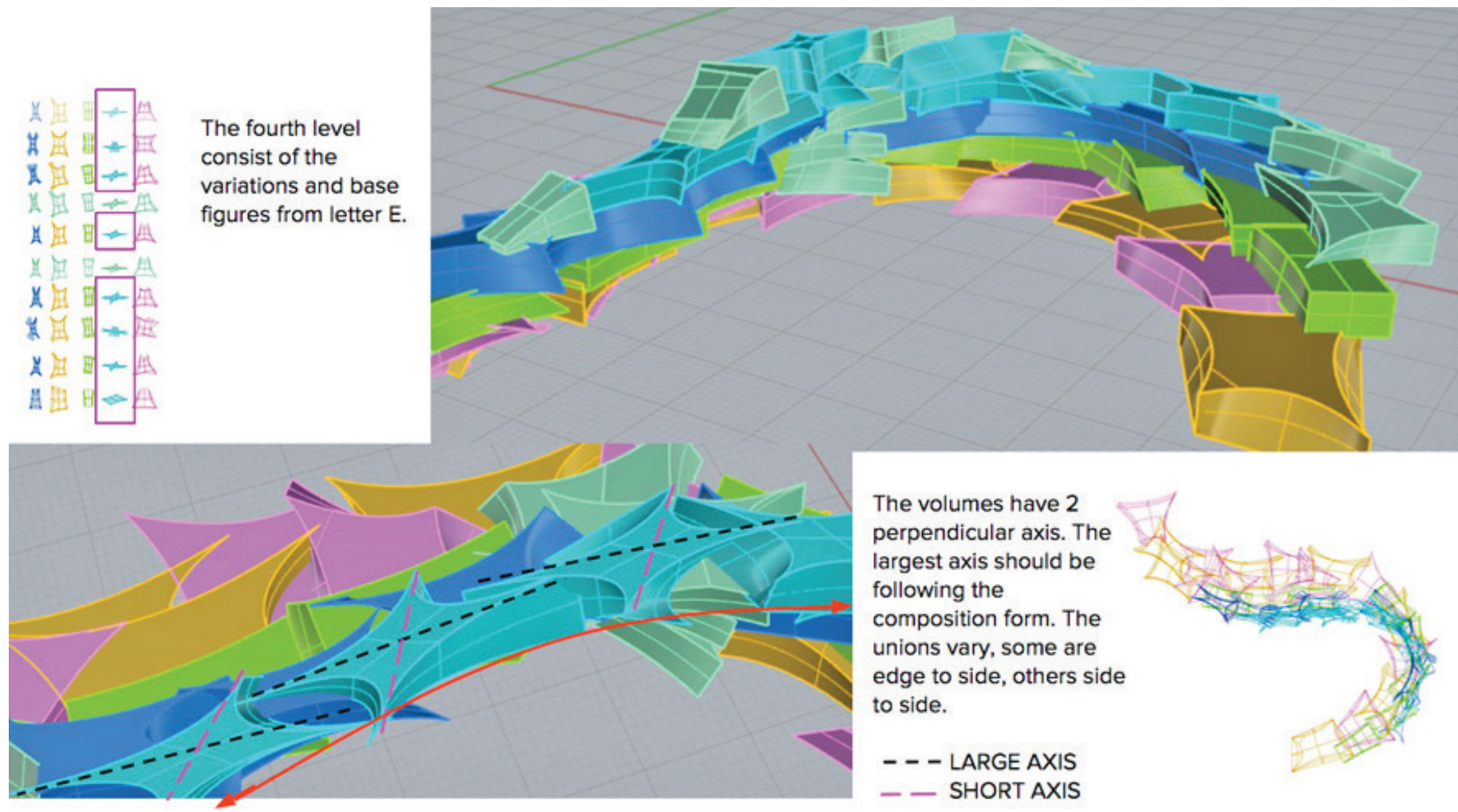

Fig. 5. Model of compositional arrangement with 50 volumes prepared for rapid prototyping. Most of the unions are intersection of the volumes with overlapping edges [Figure: S. Medina].

authors of Generative Geometry class created their own rule sets that they applied to several selected 'simple words' and then applied small incremental changes in the parameters. One way of the proposed materialization in 3D involved placing two 'simple word' geometries of the same size or with similar shapes above each other separated away with a distance parameter or a mix of distance, angle and scale parameters (Fig. 3). Then the geometries were analyzed to identify the furthest points or closest connection vectors, subsequently connecting the separated geometries and then constructing connection surfaces until a watertight solid 3D volume was acquired. The materialization steps were repeated to design a total of 50 volumes, which is a good count to construct an abstract composition (Fig. 4).

At the final stage the free form compositions were set up to fabricate them in rapid prototyping technology and represent the geometric qualities of all obtained 50 volumes (Fig. 5). Every 


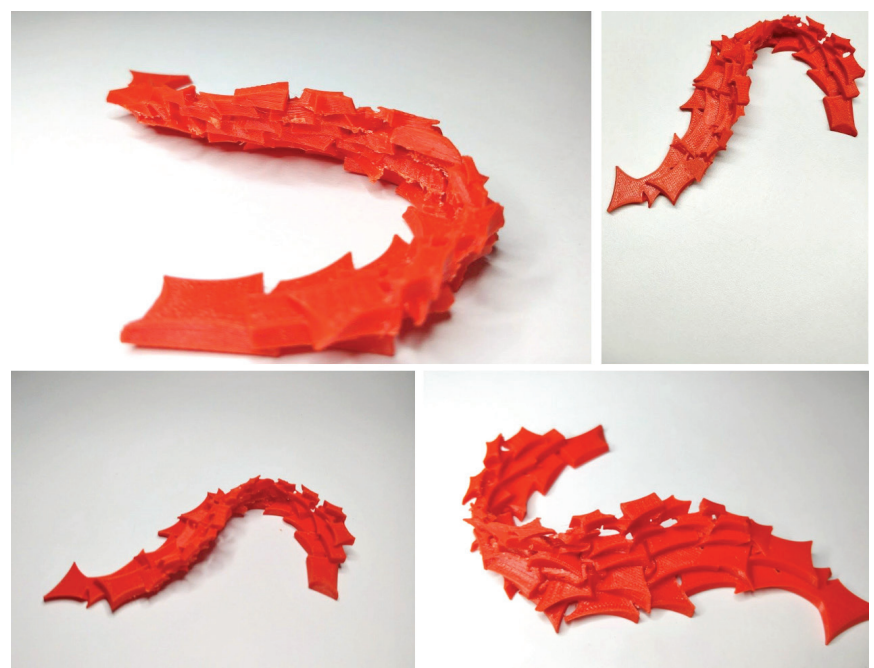

Fig. 6. Rapid prototyping model of 50 variations of simple geometric systems proliferated and materialized into 3D volumes and grouped together in a curved composition [Figure: S. Medina].

author prepared his/her compositions in Rhinoceros 3D modeling software and arranged the volumes on a footprint of approximately $15 \mathrm{~cm} \times 15 \mathrm{~cm}$. Resulted models were 3D printed in a medium resolution quality out of PLA plastics (Fig. 6).

This type of knowledge in the first steps of the architectural designer education is developed through the relationship between the advanced thinking and the advanced making, and is also being applied into an undergraduate studio taught by Prof. Daniela Frogheri in the University of Monterrey where, a process of generation of form and its materialization are concretized into the design and the fabrication of full scale pavilions [6]. Usually these pavilions measure up to $27 \mathrm{~m}^{3}$, have $2,5 \mathrm{~m}$ of height, they are self supporting and without foundations, can be totally disassembled and be placed outside as well as inside the rooms, and that can be assembled by students themselves without any help of the professionals. The morphology of such pavilions includes the parametrically generative and associative design, and they are entirely fabricated by the help of the CAM technologies (Fig. 7). Students who have undergone such experience have a more profound understanding of the curriculums developed to create unique workflows that may be applied later on in their career for basically any project in any scale and with any function.

The traditional arrangement of the main design phases is as follows: predesign, schematic design, design development, and construction of document phases. Nonetheless, each design project may undergo a particular arrangement of phases and design processes depending on its objectives and priorities [7]. Learning the $\mathrm{CAD} / \mathrm{CAM}$ application in practice is more oriented towards the usage of this technology as a creative tool for expressing better artistic ideas, and the classes of Generative Geometries implement this concept very well. Parametric design opens up a novel set of opportunities. It enables architects to study causes of problems and their relationships to, and dependencies on other elements directly [8]. Author believes that this knowledge of digital CAD/CAM literacy and parametric design are few of the

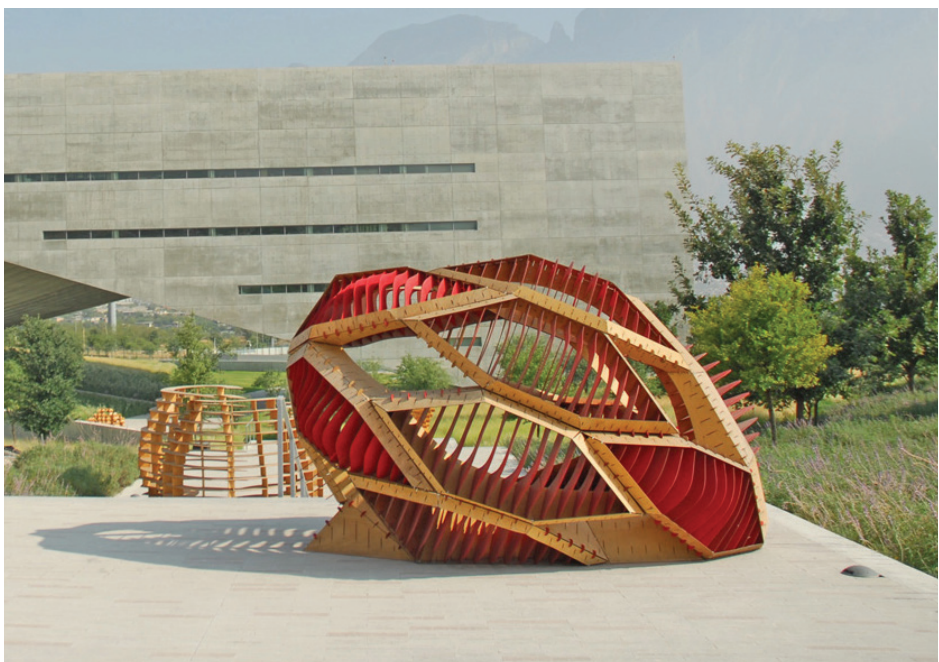

Fig. 7. Pavilion project tutored by Prof. Daniela Frogheri in the University of Monterrey in spring semester 2015 [Figure: A. Riekstins].

main important essential skills that design offices will be looking for of their future employees in the year 2020 and onwards, once this generation of architects who currently in the second study year will graduate and look for their employment.

\section{Conclusion and Future Work}

The application of advanced modeling techniques in teaching architectural design is an ongoing academic research that is setting out new dimensions for future work - where the developed workflow has to be regularly updated based on the newest trends and the usage of technology in architecture: 3D modeling, rapid prototyping and advanced representation techniques. With the abovementioned the author is proposing the following conclusions:

1. $\mathrm{CAD} / \mathrm{CAM}$ paradigm sets new technical challenges for architects, making them to resolve structure and constructability, and implement that into design.

2. Parametric design is an excellent platform for form finding, as design proposals can be explored in an efficient way by changing the variables.

3. Strong theoretical knowledge basis of mathematics and geometry supports architectural design creativity.

Further work has to be devoted to critical analyses and systematizing of the obtained results.

1. The academic advances have to meet the expectations of the leading architectural design offices and match the demand in future market.

2. Existing teaching methods must be regularly reviewed and updated to include the latest teaching and technological achievements, by collecting the feedback of the study project outcomes.

3. The processes of innovative form finding through developing of geometrical systems must be documented and elaborated further. 


\section{ACKNOWLEDGements}

All of the students in University of Monterrey from first and second generation of Generative Geometry classes in study years 2016 and 2017 contributed to the paper by offering their eager outlook and participating in constructing innovative ideas.

\section{REFERENCES}

1. Maeda, J. Design education in the post-digital age. Design Management Journal, Vol. 13, Issue 3, 2002, pp. 39-45.

2. Stavric, M., Marina, O. Parametric Modeling for Advanced Architecture. International Journal of Applied Mathematics and Informatics, Vol. 5 , Issue 1, 2011, pp. 9-16.

3. Özbaki, C., Cağdas, G., Kilimci, E. Comparing Design Productivity: Analog and Digital Media. Megaron, Vol. 11, Issue 3, 2016, pp. 398-411. doi:10.5505/megaron.2016.69188

4. Grobman, Y. J., Ron, R. Digital Form Finding - Generative use of simulation processes by architects in the early stages of the design process. eCAADe 2011 Respecting Fragile Places : education and research in computer aided architectural design in Europe, 2011, pp. 107-115.

5. Braumann, J., Brell-Cokcan, S. Parametric Robot Control: Integrated $\mathrm{CAD} / \mathrm{CAM}$ for Architectural Design. Proceedings of the 31st Annual Conference of the ACADIA, 2011, pp. 242-251.

6. Frogheri, D., Estévez, A. T. Between the advanced thinking and the advanced making. SIGraDi 2016, XX Congreso de la Sociedad Ibero-americana de Gráfica Digital, 2016, pp. 219-226.

7. Soliman, A. M. Appropriate teaching and learning strategies for the architectural design process in pedagogic design studios. Frontiers of Architectural Research, Vol. 6, 2017, pp. 204-217. doi:10.1016/j.foar.2017.03.002

8. Schnabel, M. A. Parametric Designing in Architecture. CAADFutures'07, 2007, pp. 237-250. doi:10.1007/978-1-4020-6528-6_18

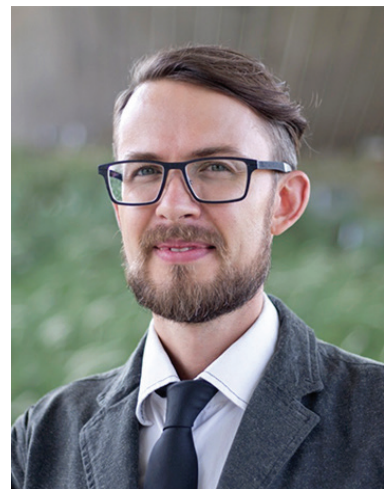

Arne Riekstins obtained the PhD degree in Achitecture from Riga Technical University (RTU) in 2011 with thesis "Digital Systems in Contemporary Architecture", M. Sc. Arch. degree from RTU in 2007 and M. BioDigi. Arch. degree from Universitat Internacional de Catalunya in 2008, Dipl. Arch. degree and B. Arch. degree from RTU in 2006 and 2004. Major field of his study is Digital Architecture. His research focuses on the $\mathrm{CAD} / \mathrm{CAM}$ paradigm where contemporary architects are creating their own unique digital tools for architectural design, investigates the new hybrid directions in architecture and how to design technically advanced objects. Dr. Arne Riekstins emphasizes that digital systems are creative working tools and is implementing this principle in his academic practice.

Since 2015 he has been a full time Professor at the University of Monterrey, Mexico (since 2015). In 2006-2015 he was a lecturer at the Faculty of Architecture and Urban Planning, Riga Technical University. He had given guest lectures in universities in Trondheim, Norway and Oulu, Finland. Since 2006 he has been a private architect and owner of Hybrid Space architecture. He has participated in numerous scientific conferences and is the author of more than 15 scientific publications, including a monography 'Arquitectura Aberrante'.

- Riekstins, A. Non-Standard Parametric Surface Design and FabricationIn Search of New Forms and Morphologies in Teaching Digital Design. $3 r d$ International Conference of Biodigital Architecture \& Genetics [A. T. Estévez, ed.]. Barcelona: Bubok, 2017, pp. 42-53.

- Riekstins, A. Steps Towards Genetic Architecture. International Scientific Conference Ecological Architecture 2011. Kaunas: KUT, 2011, pp. 13-17.

- Riekstins, A. Evolutionary Computation Design = Projektēšana, izmantojot evolucionārās skaitlošanas metodi. Scientific Journal of Riga Technical University : Series 10: Architecture and Urban Planning = RTU Zinātniskie raksti : 10. sērija: Arhitektūra un Pilsētplānošana. Rīga: RTU, 2011., Vol. 5 = 5. sēj., pp. 83-87, 144.-146. lpp.
Contact Data

\section{Arne Riekstins}

Centro Roberto Garza Sada

Universidad de Monterrey

Address: Av. Ignacio Morones Prieto 4500 Pte., 66238 San Pedro Garza García, Nuevo Leon, Mexico

Phone: +52 (81) $82151450,+37129235265$

E-mail: arne.riekstins@udem.edu 